\title{
CORRIGENDUM
}

\section{Enantioselective preparation and chemoselective cross-coupling of 1,1-diboron compounds}

Jack Chang Hung Lee, Robert McDonald and Dennis G. Hall

Nature Chemistry 3, 894-899 (2011); published online 25 September 2011; corrected after print 10 May 2013.

In the version of this Article originally published, in Table 1, the ferrocene-based ligands 4, 5, 7 and 8 should have had 1,2-substituted cyclopentadienyl rings rather than 1,3-substituted. This error has been corrected in the HTML and PDF versions of this Article.

\section{CORRIGENDUM}

\section{Simultaneous structure-activity studies and arming of natural products by $\mathrm{C}-\mathrm{H}$ amination reveal cellular targets of eupalmerin acetate}

Jing Li, Justin S. Cisar, Cong-Ying Zhou, Brunilda Vera, Howard Williams, Abimael D. Rodríguez, Benjamin F. Cravatt and Daniel Romo

Nature Chemistry 5, 510-517 (2013); published online 19 May 2013; corrected after print 22 May 2013.

In the print version of this paper, the stereochemical configuration of the $\beta$-lactone starting material 7 is drawn incorrectly $((R)-(-)$-3-hydroxy-4,4,4-trichlorobutyric $\beta$-lactone purchased from Aldrich was used in this work). As a result, the stereochemical configurations of compounds $\mathbf{8}$ and $\mathbf{9}$ and the structure of the R group in Table 1 are also drawn incorrectly. These errors have now been corrected in the HTML and PDF versions of this Article.

\section{CORRIGENDUM}

\section{Competition between model protocells driven by an encapsulated catalyst}

Katarzyna Adamala and Jack W. Szostak

Nature Chemistry 5, 495-501 (2013); published online 19 May 2013; corrected after print 3 June 2013.

In the version of this Article originally published, in Fig 3a, the description for the open triangle should have read: ' 1 equiv. dye-labelled empty vesicles + vesicles without dipeptide. This has been corrected in the HTML and PDF versions of the Article. 